\title{
Opinion \\ Proton Pump Inhibitors and Dementia - Clinical Judgment under Uncertainty
}

\section{Opinion}

I write driven by the impact, in daily medical gastroenterological practice, of the recent controversy between Proton Pump Inhibitors (PPI) use and increased risk of dementia. I experienced a wave of patient interest in this subject during the consultations, reflecting the news generated by the lay press or even communication via social networks. In summary, some recent cohort studies have found an association between PPI use and increased risk for dementia compared to patients who did not use this medication, with a Hazard Ratio (HR) $1.38,95 \%$ confidence interval (CI) 1.04-1.83] in the study of Haenisch B et al., ${ }^{1}$ and HR, $1.4495 \%$ CI, 1.36-1.52; $\mathrm{P}<.001$ ) in the study of Gomm W et al., ${ }^{2}$ Given that the PPI are among the most frequently used classes of drugs and due to the greater burden of dementia on public health, the observed repercussion was a natural consequence, and I am writing about how this information reaches patients, and how they interpret it. ${ }^{3}$ This is the cause of my concern. To what they ask us - or affirm - during the consultation: "Doc, PPIs cause dementia!", how should we guide them? And to complement the complexity of the matter, recent analysis of data from the Nurses' Health Study II did not observe the convincing association between PPI use and cognitive function, and do not support the suggestion that PPI use increases dementia risk. $^{4}$

How to approach an open scientific question, but with great repercussion in the lay media? There is sharing of data from scientific studies during the construction of knowledge, which may appear to be ambiguous or conflicting in information. Even though there has been a rapid response to clarification in the academic environment, as in a comment that concluded that "the risk-benefit calculus for appropriate use of PPIs by older individuals should remain unchanged", 5,6 what we note was the transformation, if so I can say, or the transmutation of scientific information into news. Information, even scientific information, is democratized. And this is great! It makes even more relevant the role of the physician, as his patient's counselor, who is to deliver the message of the researchers properly decoded, making something difficult easy by logically selecting the data; thus clarifying using information. ${ }^{7}$

Clinical practice shows that in most cases, due to technical ignorance or the need to raise the audience, the simplification of complex subjects can lead to hasty attitudes generated by the patient's fear. I believe it gives us the opportunity to interact with the patient and make the difference, by the professional and individualized guidance that the electronic media cannot offer. In this sense, the critical analysis of the scientific information, passing through the medical sieve and with interest in the patient's health, respecting their preferences and opinions, is the most important. In practical terms, campaigns were triggered by medical entities (AGA) in response - in summary: Reassure patients that you prescribed the PPI for a clear-cut indication, in the lowest possible dose, and for shortest time; Educate patients that, when PPIs are indicated, benefits outweigh risks; Keep conversation channels open with patients. the medication should not be stopped without discussion with the doctor; Recommend that patients also consider life-style modifications that may reduce or eliminate the need for PPIs for long-term use). ${ }^{8}$
Volume 9 Issue I - 2018

Ricardo Teles Schulz*

Universidade de São Paulo, Brazil

Correspondence: Ricardo Teles Schulz, Clinics Hospital, Universidade de São Paulo, Brazil, Email ricardo-schulz@hotmail.com

Received: September 10, 2017 | Published: January 31, 2018

We must understand that, about true or false "polemics" in a given medical subject, the patient may be vulnerable to simplistic causeand-effect analysis, without nuances of quality of scientific evidence, complexity of diagnoses (eg dementia), interpretation of statistical concepts and multifactorial influences in individualized cases, with a careful risk-benefit analysis. The patient may not be aware of such notions as "causality" and "statistical association". What we often have are preconceived ideas that are difficult to clarify, and consequently the construction of beliefs, which assume a varnish of pseudo-science - because they start from scientific studies but conclude without the commitment to scientific rigor. It seems that the final lines of the conclusions of one of the cited studies are ignored; there it is written "Randomized, prospective clinical trials are needed to examine this connection in more detail". ${ }^{2}$ Do we already have them, these RTC? No, not yet. These, if done, could either confirm or refute the current results. But the available studies, with less quality of evidence, do not allow extrapolate a cause-and-effect relationship. We do not want, by impulse, ignorance or vanity to extract an answer from studies that were not designed to answer it.

This controversy is neither the first nor the last. In a broader view, the absence of observation of these nuances and the lack of education in science provokes the popular impression of permanent contradiction in scientific concepts and "news". Feynman was already warning, saying that the first principle is not to deceive yourself and you are the easiest person to be deceived. We must try to guide ourselves in the search for the closest to the truth that we can reach, and no closer to what is simply only more attractive or more desirable to us. In the words of João Manuel Cardoso Martins, MD: "Science will always be uncertain, imprecise and partial, therefore unlimited, transitory and evolutionary". ${ }^{9}$ Empiricism, rationalism, imagination and verification, these complementary, it is from their conflict that the vitality of science is born.

\section{Acknowledgement}

None. 


\section{Conflicts of Interest}

None.

\section{References}

1. Haenisch B, von Holt $\mathrm{K}$, Wiese B, et al. Risk of dementia in elderly patients with the use of proton pump inhibitors. Eur Arch Psychiatry Clin Neurosci. 2014;265(5):419-428.

2. Gomm W, von Holt K, Thomé F, et al. Association of Proton Pump Inhibitors with Risk of Dementia A Pharmacoepidemiological Claims Data Analysis. JAMA Neurol. 2016;73(4):410-416.

3. Mazer-Amirshahi M, Mullins PM, van den Anker J, et al. Rising rates of proton pump inhibitor prescribing in US emergency departments. Am J Emerg Med. 2014;32(6):618-622.
4. Lochhead P, Hagan K, Joshi AD, et al. Association Between Proton Pump Inhibitor Use and Cognitive Function in Women. Gastroenterology. 2017;153(4):971-979.

5. Goldstein FC, Steenland K, Zhao L, et al. Proton Pump Inhibitors and Risk of Mild Cognitive Impairment and Dementia. J Am Geriatr Soc. 2017;65(9):1969-1974.

6. Atri A, Gerson LB. Continued Questions About Whether Avoidance of Proton Pump Inhibitors Can Reduce Risk of Dementia. Gastroenterology. 2016;151(3):555-558.

7. How to Talk with Your Patients About PPIs and Dementia. American Gastroenetrological Association. 2017.

8. http://www.crmpr.org.br/publicacoes/cientificas/index.php/iatrico 